\title{
Prevalence and determinants of osteoporosis among men aged 50 years or more in Sri Lanka: a community-based cross-sectional study
}

\author{
Sarath Lekamwasam • Lalith Wijayaratne • \\ Mahinda Rodrigo $\cdot$ Udual Hewage
}

Received: 19 June 2009 / Accepted: 4 September 2009/Published online: 20 November 2009

(C) The Author(s) 2009. This article is published with open access at Springerlink.com

\begin{abstract}
Summary This study, based on phalangeal bone mineral density (BMD) of 1,174 community dwelling male volunteers aged 50 years or more from seven provinces in Sri Lanka, shows $5.8 \%$ prevalence of osteoporosis among them. Advancing age, less physical activity, and low body weight were associated with low BMD. Men with larger families were more likely to have a lower bone mineral density.

Purpose The prevalence of osteoporosis among Sri Lankans is not well-known. We wished to estimate the prevalence and determinants of osteoporosis among older men in Sri Lanka.

Methods One thousand one hundred seventy-four healthy, community dwelling male volunteers, aged 50 years or more from seven out of nine provinces in Sri Lanka underwent phalangeal bone mineral density estimation using an AccuDXA ${ }^{\circledR}$ scanner. We calculated T scores using the local reference data, and subjects with $\mathrm{T}$ score equal or less than -2.5 was considered to have osteoporosis.
\end{abstract}

\author{
S. Lekamwasam $(\square)$ \\ Faculty of Medicine, Center for Metabolic Bone Diseases, \\ Galle 80000, Sri Lanka \\ e-mail: sarathlk@sltnet.lk \\ L. Wijayaratne \\ Department of Rheumatology, National Hospital, \\ Colombo, Sri Lanka \\ M. Rodrigo \\ Faculty of Medicine, Department of Anatomy, \\ Galle, Sri Lanka \\ U. Hewage \\ Department of Medicine, Mount Isa Hospital, \\ Queensland, Australia
}

Results Sixty-six men (5.8\%) were detected to have osteoporosis. In contrast to men in the highest tertile of bone mineral density, men in the lowest tertile were older (60.0 versus 55.8 years, $p<0.001)$, lighter $(56.3$ versus $65.6 \mathrm{~kg}, p<0.001)$, less physically active $(16.1 \%$ versus $5.5 \%, p<0.001)$ and had larger families consisting of four or more children ( $36 \%$ versus $20.9 \%, p<0.001)$. Smoking, alcohol, or milk consumption showed no association with bone mineral density.

Conclusions We report 5.8\% prevalence of osteoporosis among men older than 50 years in Sri Lanka, and advancing age, less physical activity, and low body weight were associated with low bone mineral density. Men with larger families were more likely to have a lower bone mineral density.

Keywords Male osteoporosis $\cdot$ Sri Lanka $\cdot$ Cross-sectional study - AccuDXA

\section{Introduction}

Although osteoporosis is generally regarded as a disease of postmenopausal women, mortality and morbidity associated with osteoporosis-related fractures are higher among men than in women $[1,2]$. While $20-25 \%$ of hip fractures occur in men, the overall mortality following hip fracture in men is about $20 \%$ in the first 12 months [1, 3]. According to Kanis et al., the overall mortality during the first 6 months following hip fracture is higher in men when compared to women in the same age category [2]. Men with osteoporosis-related fractures are a heavy burden on current health care systems. In Sweden, the bed occupancy of men with osteoporotic fractures was similar to that of prostate cancer [4]. Apart from hip fracture, men are prone to vertebral fractures, and in a prospective study in Rotterdam, 
the incidence of vertebral fractures among men between 55 and 65 years was 5.2/1,000 person-years [5].

Unlike in women, prevalence and determinants of osteoporosis among men are not well-documented. Although, World Health Organization developed criteria in 1997 to unify the diagnosis of osteoporosis, they are applicable only for postmenopausal female populations [6]. In previous studies, the prevalence of osteoporosis among men varied depending on the skeletal site used to measure bone mineral density (BMD) and the reference data applied to calculate T scores [7]. Furthermore, there was no uniform opinion on the $\mathrm{T}$ score threshold that should be applied when making the diagnosis of osteoporosis in men [8]. In 2002, International Society of Clinical Densitometrists (ISCD) recommended using male reference data to calculate $\mathrm{T}$ scores and cut-off value of -2.5 to confirm the diagnosis of osteoporosis in male subjects [9].

Osteoporosis, in general, is not a high priority in South Asian countries, and the prevalence of osteoporosis among men in these countries is not well-documented. Furthermore, the restricted availability of duel-energy X-ray absorptiometry (DXA) in these countries would have contributed to the scarcity of data on osteoporosis. Community-based studies are required to estimate prevalence, and the burden of osteoporosis in South Asian countries in order to convince health care providers that osteoporosis is a health priority. The current study was carried out to estimate the prevalence of osteoporosis among men aged 50 years or more, selected from seven provinces in Sri Lanka.

\section{Methods}

The Community Osteoporosis Survey conducted between October 2004 and October 2005 recruited community dwelling men and women aged more than 20 years from seven out of nine administrative provinces in Sri Lanka. The northern and eastern provinces were not included due to security concerns. Two different geographical areas, one representing rural population and other urban, were selected from each province. These areas were randomly selected based on the classification used by the Department of Census and Statistics in Sri Lanka during the 2001 census. Consenting men and women had their weight measured while wearing light cloths and after removing footwear. A brief heath-related questionnaire was filled and BMD and bone mineral content (BMC) of the middle phalanx of the middle finger of the nondominant hand were measured using an AccuDEXA ${ }^{\circledR}$ scanner (Schick Technologists, USA). The questionnaire inquired the historical risk factors of osteoporosis such as smoking habits, alcohol consumption, educational status, social class, dairy consumption, and physical activity. For educational status, the advanced level exam (or its previous equivalents) was taken as the cut-off point. Time spent, currently, for selected physical activities such as walking, manual work, reading, sleeping, etc. was inquired, and subjects were categorized to three groups; "very active," "moderately active," and "less active," depending on their activities. Subjects in the "very active" group engaged in physical activities resulting excessive sweating for more than an hour for 5-7 days a week, while subjects in the "moderately active" and "less active" groups engaged in such activities for 3-4 or less than 3 days a week, respectively. Frequency of current dairy (milk, cheese, and yogurt) consumption was inquired and recorded as a categorical variable. We intended to include a minimum of 500 men from each province, and in many provinces, we exceeded this number as we had to include all subjects gathered in these scanning centers. Public announcing system was used 2 to 3 days ahead of the planned visit to explain the nature and the purpose of the study to people in the area.

AccuDEXA $^{\circledR}$ was selected for this project due to practical reasons. The device is portable and operator friendly which are advantages when performing a DXAbased community study. AccuDXA ${ }^{\circledR}$ uses two X-ray energies to estimate BMD in cortical-rich middle phalanx and has high measurement accuracy. The device is supplied with software, which automatically scans the built-in phantom to ensure the accuracy of BMD estimations. A trained technician attached to this study verified this process on each scanning day before collecting data.

The clinical applications of BMD and BMC measured with AccuDXA have been examined earlier. Mulder et al. in 2000 showed significant correlations, ranging from 0.53 to 0.73 , between phalangeal BMD and BMDs in spine, total hip, femoral neck, and mid radius. Furthermore, the same study found the ability of phalangeal BMD to detect osteoporosis if appropriate $\mathrm{T}$ score cut-off values are used [10]. In a case control study, phalangeal BMD predicted recent vertebral fractures, and this association was not affected by the presence of osteoarthritis in hand joints [11]. Versluis et al. also found phalangeal BMD to predict vertebral deformities as closely as femoral neck BMD [12].

Data of men aged 50 years or more were considered for this analysis. Men with inflammatory arthritis, malabsorption, hyperthyroidism, hyperparathyroidism, chronic liver diseases, renal impairment, or long standing diseases of inflammatory nature were excluded from the analysis. Similarly, those who had taken drugs such as vitamin D, pharmacological doses of calcium, thiazide diuretics, thyroxin, antiepileptics, systemic corticosteroids, or antiresorptive drugs were excluded (total number of exclusions $=125$ ). Subjects who had asthma or previous fracture were not 
excluded from the study. Finally, BMD data of 1147 men were included in this analysis.

In order to obtain local reference data to calculate $\mathrm{T}$ scores, we analyzed BMD of all men aged 20 years or more recruited to the original study. Mean BMD and standard deviations of age groups 20-29, 30-39, 40-49, 50-59, and 60-69 were calculated. The highest BMD was detected in $30-39$ age group $(n=1,111)$, and mean BMD and standard deviation $\left(0.603\right.$ and $0.061 \mathrm{~g} / \mathrm{cm}^{2}$, respectively) of this age category were used as reference data.

$\mathrm{T}$ score of phalangeal BMD was calculated using the following formula.

$\mathrm{T}$ score $=(\mathrm{BMD}$ of the subject -0.603$) / 0.061$

Subjects were considered to have osteoporosis when their phalangeal BMD was equal or less than -2.50 .

\section{Statistical analysis}

Regression model was fitted with age and weight as independent variables and BMD as the dependent variable to examine the associations between these variables. Subjects were categorized to three age groups; $50-59(n=$ $810), 60-69(n=250), 70$ and above $(n=87)$, and mean BMDs in different groups were compared using analysis of variance with Bonferroni correction. The association between BMD and physical activity, education level, and social habits such as smoking and alcohol consumption was examined by cross tabulating these categorical variables in the tertiles of BMD. Chi-square test was used to compare categorical data in different groups. Two-tailed $p<0.05$ was taken as the level of statistical significance (except in multiple comparisons) and the SPSS version 10 for Windows was used for all calculations.

Ethical approval for the study was obtained from the Ethics Review Committee of the Faculty of Medicine, Galle, Sri Lanka. All subjects signed a consent form before taking part in the study.

\section{Results}

Age of the subjects ranged from 50 to 84 with mean (SD) of 57.6 (6.6) years (Table 1). BMD and BMC showed gradual and significant decline with advancing age (Table 2). In the regression analysis, difference of age by 1 year was associated with BMD difference (inverse association) of $0.002 \mathrm{~g} / \mathrm{cm}^{2}$ (standard error of mean $0.0004, p<0.001$ ) while $1 \mathrm{~kg}$ change in body weight was associated with a BMD difference (positive association) of $0.002 \mathrm{~g} / \mathrm{cm}^{2}$ (standard error of mean 0.0003, $p<0.001$ ). Age and weight together accounted for $20 \%\left(r^{2}=0.20\right)$ variation in BMD.
Table 1 Characteristics of the 1,147 men included in the analysis

\begin{tabular}{lc}
\hline Measure & Value \\
\hline Mean (SD) age (years) & $57.6(6.6)$ \\
Mean (SD) weight $(\mathrm{kg})$ & $61.3(10.8)$ \\
Mean (SD) BMD $\left(\mathrm{g} / \mathrm{cm}^{2}\right)$ & $0.568(0.723)$ \\
Mean (SD) BMC $(\mathrm{g})$ & $2.10(0.39)$ \\
Percentage of current smokers & $169(25.6 \%)$ \\
Percentage of past smokers & $146(22.1 \%$ \\
Percentage of current alcohol users & $341(51.6 \%)$ \\
Percentage of past alcohol users & $82(12.4 \%)$ \\
\hline
\end{tabular}

Of 1,147, 66 men had $\mathrm{T}$ score equal or less than -2.50 ; hence, the prevalence of osteoporosis was estimated to be $5.8 \%$. The prevalence of osteoporosis showed a steady increase in successive age groups (Table 2). When compared with men in the highest tertile of BMD, men in the lowest tertile were older, lighter, and less physically active. Further, compared to men in the highest tertile, men in the lowest tertile had bigger families (Table 3). The consumption of milk, level of education, socio-economic background, smoking habit, and alcohol consumption were not significantly different in the tertiles of BMD.

\section{Discussion}

We demonstrated an age-related, gradual, and significant reduction of phalangeal BMD in this group of healthy men selected from the community. One year age difference or $1 \mathrm{~kg}$ change in body weight was associated with $0.002 \mathrm{~g} / \mathrm{cm}^{2}$ change in BMD. In the study sample, 5.8\% subjects had osteoporosis, and the prevalence of osteoporosis showed an exponential rise with advancing age. While high degree of physical activity was associated with higher BMD, increased family size (four or more children) had a negative effect on BMD.

Although the north and east provinces were not included in the data collection due to security reasons, it would not reduce the external validity of our findings. North and east have predominantly ethnic Tamil and Moor populations, and we were able to include these ethnic groups (19\% Tamils and $08 \%$ Moors) from other provinces. These figures are very close to the proportions of these ethnic groups found in the country's population.

Epidemiological studies on male osteoporosis vary methodologically with regards to sample size, technology used to measure BMD, and reference data used to calculate $\mathrm{T}$ scores. Hence, prevalence figures reported in these studies have shown a wide variation. The $5.8 \%$ prevalence of osteoporosis we report in this study is comparable with the previous study by Siribaddana et al., reporting $4 \%$ prevalence of male 
Table 2 BMD, BMC, and percentage of men with osteoporosis in different age groups

\begin{tabular}{lcccc}
\hline Measurement & 50-59years $(n=810)$ & $60-69$ years $(n=250)$ & 70 and above $(n=87)$ & $P$ value \\
\hline BMC $(\mathrm{g})$ & $2.13(0.38)$ & $2.07(0.41)$ & $1.89(0.40)$ & $<.522(0.079)$ \\
BMD $\left(\mathrm{g} / \mathrm{cm}^{2}\right)$ & $0.576(0.068)$ & $0.558(0.077)$ & $18.4 \%$ & $<0.001^{\mathrm{a}}$ \\
Percent with osteoporosis & $3.3 \%$ & $9.2 \%$ & $<0.001^{\mathrm{a}}$ \\
\hline
\end{tabular}

${ }^{a}$ Comparison of three age groups using ANOVA with Bonferroni correction

${ }^{\mathrm{b}}$ Comparison of three age groups using Chi-square test

Table 3 Age, weight, socio-economic statues, and social habits in the thirds of BMD of 1,147 men

\begin{tabular}{|c|c|c|c|c|}
\hline Measurement & $\begin{array}{l}\text { The lowest } 1 / 3 \text { of BMD } \\
(n=382)\end{array}$ & $\begin{array}{l}\text { The middle } 1 / 3 \text { of BMD } \\
(n=383)\end{array}$ & $\begin{array}{l}\text { The highest } 1 / 3 \text { of BMD } \\
(n=382)\end{array}$ & $p$ value \\
\hline Mean (SD) BMD (g/cm²) & $0.484(0.043)$ & $0.570(0.019)$ & $0.649(0.036)$ & $<0.001^{\mathrm{a}}$ \\
\hline Mean (SD) BMC (g) & $1.67(0.26)$ & $2.11(0.16)$ & $2.49(0.27)$ & $<0.001^{\mathrm{a}}$ \\
\hline Mean (SD) age (years) & $60.02(8.06)$ & $58.6(6.48)$ & $55.81(5.21)$ & $<0.001^{\mathrm{a}}$ \\
\hline Mean (SD) weight (kg) & $56.34(9.33)$ & $61.89(9.65)$ & $65.61(11.2)$ & $<0.001^{\mathrm{a}}$ \\
\hline \multicolumn{5}{|l|}{ Level of education } \\
\hline Below advanced level & $150(68.2 \%)$ & $154(69.4 \%)$ & $149(68.0 \%)$ & \multirow[t]{3}{*}{$0.21^{\mathrm{b}}$} \\
\hline Up to advanced level & $47(21.4 \%)$ & $52(23.4 \%)$ & $59(26.9 \%)$ & \\
\hline Beyond advanced level & $23(10.5 \%)$ & $16(7.2 \%)$ & $11(5.0 \%)$ & \\
\hline \multicolumn{5}{|l|}{ Social status } \\
\hline Middle class & $209(95 \%)$ & $210(95 \%)$ & $214(97.7 \%)$ & \multirow[t]{2}{*}{$0.27^{\mathrm{b}}$} \\
\hline Above or below middle class & $11(5 \%)$ & $11(5 \%)$ & $5(2.3 \%)$ & \\
\hline \multicolumn{5}{|l|}{ Physical activity } \\
\hline Very active & $16(7.3 \%)$ & $21(9.5 \%)$ & $28(12.8)$ & \multirow[t]{3}{*}{$0.001^{\mathrm{b}}$} \\
\hline Moderately active & $167(76.6 \%)$ & $183(83.2 \%)$ & $178(81.7 \%)$ & \\
\hline Less active & $35(16.1 \%)$ & $16(7.3 \%)$ & $12(5.5 \%)$ & \\
\hline \multicolumn{5}{|l|}{ Milk consumption } \\
\hline Not consumed & $33(15.1 \%)$ & $25(11.3 \%)$ & $24(11.0 \%)$ & \multirow[t]{4}{*}{$0.87^{\mathrm{b}}$} \\
\hline Less than once a day & $53(24.3 \%)$ & $55(24.9 \%)$ & $58(26.6 \%)$ & \\
\hline 1-2 times per day & $104(47.7 \%)$ & $114(51.6 \%)$ & $110(50.5 \%)$ & \\
\hline$>2$ times per day & $28(12.8 \%)$ & $27(12.2 \%)$ & $26(11.9 \%)$ & \\
\hline \multicolumn{5}{|l|}{ Number of children } \\
\hline Nil & $4(1.9 \%)$ & $7(3.3 \%)$ & $8(3.8 \%)$ & \multirow[t]{4}{*}{$<0.001^{\mathrm{b}}$} \\
\hline 1-3 children & $132(62.3 \%)$ & $123(58.3 \%)$ & $156(74.3 \%)$ & \\
\hline 4-5 children & $54(25.5 \%)$ & $69(32.7 \%)$ & $42(20 \%)$ & \\
\hline$>5$ children & $22(10.4 \%)$ & $12(5.7 \%)$ & $4(1.9 \%)$ & \\
\hline \multicolumn{5}{|l|}{ Smoking } \\
\hline Current smoker & $63(28.8 \%)$ & $56(25.8 \%)$ & $50(22.8 \%)$ & \multirow[t]{3}{*}{$0.71^{\mathrm{b}}$} \\
\hline Past smoker & $48(21.9 \%)$ & $47(21.7 \%)$ & $51(23.3 \%)$ & \\
\hline Never smoked & $108(49.3 \%)$ & $114(52.5 \%)$ & $118(53.9 \%)$ & \\
\hline \multicolumn{5}{|l|}{ Alcohol } \\
\hline Current user & $110(50.7 \%)$ & $113(52.1 \%)$ & $118(55.1 \%)$ & \multirow[t]{3}{*}{$0.77^{\mathrm{b}}$} \\
\hline Past user & $28(12.9 \%)$ & $31(14.3 \%)$ & $23(10.7 \%)$ & \\
\hline Never used & $79(36.4 \%)$ & $73(33.6 \%)$ & $73(34.1 \%)$ & \\
\hline
\end{tabular}

${ }^{a}$ Comparison of three groups using ANOVA with Bonferroni correction

${ }^{\mathrm{b}}$ Comparison of three groups using Chi-square test 
osteoporosis in Sri Lanka [13]. Tenenhouse et al. found 6.6\% Canadian males, older than 50 years, to have osteoporosis either in the spine or femoral neck [14], while Pongchaiyakul et al. detected $4.6 \%$ of Thai men to have osteoporosis in the spine and $12.6 \%$ in the femoral neck [15]. The prevalence of osteoporosis among Spanish males aged 50 years or more was $8.1 \%[16]$.

A discrepancy in the prevalence of osteoporosis between skeletal sites was seen in previous studies [14, $15,17]$. Calculations in our study are based on BMD measured in a peripheral site in the appendicular skeleton and prevalence in other sites such as spine or hip could be different. We were able to get local reference data from the same study to calculate T scores, and this would enhance the external validity of our data. In a previous study, the prevalence of osteoporosis among 1,084 Chinese males aged 50 years or more varied according to the reference data selected. While Chinese reference data estimated prevalence of osteoporosis at the spine, total hip, femoral neck, trochanter, and intertrochanter to be between $1.8 \%$ and $6.3 \%$, US non-Hispanic white men (NHANES III) reference data estimated different and significantly higher prevalence rates in all skeletal sites [18]. In the USA, the prevalence of male osteoporosis changed from $1-4 \%$ to $4-6 \%$ when male reference data were applied instead of female reference data [7]. Siribaddana et al. found a wide variation in the prevalence of osteoporosis when two reference databases, one provided by the manufacturer and other local, were used [13]. In 2002, ISCD recommended using male reference data to calculate $\mathrm{T}$ scores and applying $\mathrm{T}$ score threshold of -2.5 to diagnose male osteoporosis [9]. Most of the recent studies have followed these recommendations.

We found physical activity and body weight to have a positive association with BMD among our study subjects. Positive association between BMD and physical activity among males was observed in previous studies [19]). In the same analysis, body weight was found to be positively correlated with BMD in males [19]. We found no association between BMD and either smoking or alcohol intake, and our observations are keeping with those previously observed [19]. Although previous studies found calcium intake [20] to have positive effect on BMD, we did not find a similar association. Unlike in European countries, consumption of dairy products in Sri Lanka is relatively low. Small fish and green leaves, which are relatively cheap and available throughout the year, are the main sources of calcium in the country. Although the bioavailability of calcium from these sources is low, nondairy items would still be the main source of calcium in average Sri Lankan diet. We did not have sufficient information on total dairy and nondairy calcium sources in our subjects due to the limited interaction we had with our subjects in community setting, and this would have contributed to inconclusive results.

In the categorical analysis, in comparison to men with higher BMD, men with lower BMD were more likely to have larger families (four or more children). Although, previous studies showed a negative effect of multiple pregnancies on maternal BMD [21]; association between number of child births and paternal BMD has not been examined. Marginal maternal nutrition during pregnancy and breast feeding together with effects of hormonal changes on maternal skeleton thought to be responsible for the lower BMD seen in multiparous mothers [22]. Although exact reason is unknown, poor nutrition appears to be the most plausible explanation for the association observed between paternal BMD and family size. Lower body weight, we observed among subjects with low BMD, would support this idea. Association between nutrition, body mass index and BMD has been previously observed by Coin et al. [23].

In summary, we report $5.8 \%$ prevalence of osteoporosis among males aged 50 years or more among this study sample selected from seven provinces in Sri Lanka. When compared with men with higher BMD, men with lower BMD were older, lighter, and physically less active and had larger families. These observations are based on BMD measured in a peripheral site and prevalence of osteoporosis in central sites such as spine or proximal femur could be different. Our results could be used in designing future studies on male osteoporosis in Sri Lanka.

The current study has several limitations. Crosssectional studies cannot establish casual associations, and we are unable to comment on the temporal relationships of the associations of BMD seen in this study. Only scanning centers were randomized, and we did not randomize subjects gathered in scanning centers. Furthermore, subjects were volunteers who responded to our open invitation. These would have led to selection bias and would limit the external validity of our results. Brief questionnaire that we used in community setting was not validated and gave only limited information on socioeconomic background, food habits, or physical activities and did not allow us a detailed examination of associations of BMD among our subjects. Certain relevant medical conditions, such as hypovitaminosis D or mild form of malabsorption syndrome, may have gone undetected. Furthermore, measurement of BMD was restricted to one skeletal site, and it is not a site recommended for the diagnosis of osteoporosis [24]. Prevalence of osteoporosis in more clinically relevant sites, such as spine or proximal femur, would be different from what we observed in this study. Despite these limitations, this study would provide a platform for future research in this subject in Sri Lanka. 


\section{Conflicts of interest None.}

Open Access This article is distributed under the terms of the Creative Commons Attribution Noncommercial License which permits any noncommercial use, distribution, and reproduction in any medium, provided the original author(s) and source are credited.

\section{References}

1. Seeman E (1995) The dilemma of osteoporosis in men. Am J Med 98:76S-88S

2. Kanis JA, Oden A, Johnell O, De Laet C, Jonsson B, Oglesby AK (2003) The components of excess mortality after hip fracture. Bone 32:468-473

3. Center JR, Nguyen TV, Schneider D, Sambrook PN, Eisman JA (1999) Mortality after all major types of osteoporotic fracture in men and women: an observational study. Lancet 353:878-882

4. Kanis JA, Johnell O, Oden A, De Laet C, Mellstrom D (2004) Epidemiology of osteoporosis and fracture in men. Calcif Tissue Int 75:90-99

5. Van der Klift M, De Laet CE, McCloskey EV, Hofman A, Pols HA (2002) The incidence of vertebral fractures in men and women: the Rotterdam study. J Bone Miner Res 17:1051-1056

6. Kanis JA, Melton LJ 3rd, Christiansen C, Johnston CC, Khaltaev N (1994) The diagnosis of osteoporosis. J Bone Miner Res 9:1137-1141

7. Looker AC, Orwoll ES, Johnston CC Jr, Lindsay RL, Wahner HW, Dunn WL, Calvo MS, Harris TB, Heyse SP (1997) Prevalence of low femoral bone density in older U.S. adults from NHANES III. J Bone Miner Res 12:1761-1768

8. Faulkner KG, Orwoll E (2002) Implications in the use of T-scores for the diagnosis of osteoporosis in men. J Clin Densitom 5:87-93

9. Binkley NC, Schmeer P, Wasnich RD, Lenchik L (2002) What are the criteria by which a densitometric diagnosis of osteoporosis can be made in males and non-Caucasians? J Clin Densitom 5(Suppl):S19-27

10. Mulder JE, Michaeli D, Flaster ER, Siris E (2000) Comparison of bone mineral density of the phalanges, lumbar spine, hip, and forearm for the assessment of osteoporosis in postmenopausal women. J Clin Densitom 3:373-381

11. Ohtsuka M, Michaeli D, Wasnich RD (2002) Relationship between phalangeal bone density and risk of vertebral fracture. $\mathrm{J}$ Clin Densitom 5:11-15
12. Versluis RG, Petri H, Vismans FJ, van de Ven CM, Springer MP, Papapoulos SE (2000) The relationship between phalangeal bone density and vertebral deformities. Calcif Tissue Int 66:1-4

13. Siribaddana SH, Kovas Y, Fernando DJS (2008) Quantitative ultrasound of bone and calcium intake in suburban males in Sri Lanka. Inter J of Rheumatic Diseases 11:407-413

14. Tenenhouse A, Joseph L, Kreiger N, Poliquin S, Murray TM, Blondeau L, Berger C, Hanley DA, Prior JC (2000) Estimation of the prevalence of low bone density in Canadian women and men using a population-specific DXA reference standard: the Canadian Multicentre Osteoporosis Study (CaMos). Osteoporos Int 11:897904

15. Pongchaiyakul C, Apinyanurag C, Soontrapa S, Soontrapa S, Pongchaiyakul C, Nguyen TV, Rajatanavin R (2006) Prevalence of osteoporosis in Thai men. J Med Assoc Thai 89:160-169

16. Naves M, Diaz-Lopez JB, Gomez C, Rodriguez-Rebollar A, Serrano-Arias M, Cannata-Andia JB (2005) Prevalence of osteoporosis in men and determinants of changes in bone mass in a non-selected Spanish population. Osteoporos Int 16:603609

17. El-Desouki MI, Sulimani RA (2007) High prevalence of osteoporosis in Saudi men. Saudi Med J 28:774-777

18. Zhang ZL, Qin YJ, Huang QR, Hu YQ, Li M, He JW, Zhang H, Liu YJ, Hu WW (2006) Bone mineral density of the spine and femur in healthy Chinese men. Asian J Androl 8:419-427

19. Glynn NW, Meilahn EN, Charron M, Anderson SJ, Kuller LH, Cauley JA (1995) Determinants of bone mineral density in older men. J Bone Miner Res 10:1769-1777

20. Cauley JA, Fullman RL, Stone KL, Zmuda JM, Bauer DC, Barrett-Connor E, Ensrud K, Lau EM, Orwoll ES (2005) Factors associated with the lumbar spine and proximal femur bone mineral density in older men. Osteoporos Int 16:1525-1537

21. Zhang YY, Liu PY, Deng HW (2003) The impact of reproductive and menstrual history on bone mineral density in Chinese women. J Clin Densitom 6:289-296

22. Lau EM, Cooper C (1996) The epidemiology of osteoporosis. The oriental perspective in a world context. Clin Orthop Relat Res 232:65-74

23. Coin A, Sergi G, Beninca P, Lupoli L, Cinti G, Ferrara L, Benedetti G, Tomasi G, Pisent C, Enzi G (2000) Bone mineral density and body composition in underweight and normal elderly subjects. Osteoporos Int 11:1043-1050

24. Kanis JA (2002) Diagnosis of osteoporosis and assessment of fracture risk. Lancet 359:1929-1936 